\title{
Application of geotechnical database in the city of Athens
}

\author{
A. A. Antoniou, P. G. Marinos, and M. Kavvadas \\ Geotechnical Division, Civil Engineering Department, National Technical University of Athens, \\ 42 Patission str., 106-42, Athens, Greece
}

\begin{abstract}
The paper presents a relational geotechnical database management system, which can accommodate the information derived from geotechnical investigation. It was built in Microsoft® Access environment at the Geotechnical Division of National Technical University of Athens (NTUA). Two examples of its application through Microsoft® Excel and Arcview® version 3.1 are also given.
\end{abstract}

\section{INTRODUCTION}

The information obtained from boreholes and pilot shafts can be stored in a geotechnical-geological database and can be classified into the following categories:

- Geographical (the information deals with coordinates $\mathrm{X}, \mathrm{Y}$, and elevation Z);

- Geological (the information refers to lithology, degree of weathering, colour etc); and

- Geotechnical (the information includes all the in situ and laboratory tests carried out for the specific geotechnical investigation).

The data storage requires relational tables with one or more common fields (e.g., borehole id, which is unique for every borehole). For data input, the information is classified into the following categories:

- Descriptive: the fields of the table contain text (i.e. geological description, area where the geotechnical investigation was carried out, colour, degree of weathering etc) and

- Numerical: the fields of the table contain numerical data from all the tests (in situ and laboratory) carried out in a borehole (Candela 1988; ASCE 1991; Greenwood 1988).

\section{STRUCTURE OF THE RELATIONAL DATABASE MANAGEMENT SYSTEM (RDBMS)}

At the Geotechnical Division of the National Technical University of Athens (NTUA), a relational geotechnicalgeological database has been designed in Microsoft ${ }^{\circledR}$ Access environment to accommodate the variety of information gathered during the ground investigation. So far the database contains the data of more than 700 boreholes drilled in the basin of Athens, and the final aim is to collect information from 2,000 boreholes. This pilot project can be extended to any other city and many other tables can be added to its structure depending on the user's needs.

The database consists of the following seven primary tables: BOREHOLE, REAL ID, WATER TABLE, LITHOLOGY, INSITU_TESTS, LAB_TESTS, and ROCKMASS_CLASSIFICATION. The common field that joins all those tables is borehole_id, which is unique (Fig. 1).

The table BOREHOLE contains general information on each borehole. The table REAL_ID stores the identification number of the borehole as recorded in the log. The information in WATER TABLE concerns the depth of water table during the last day of drilling, the information of a possible piezometer etc. The table LITHOLOGY refers to general information about the characteristics of the formations, i.e. its composition, colour, degree of weathering etc. The classification of rockmass proposed by the International Society of Rock Mechanics (ISRM 1981) has been applied in some fields of this table and the user must follow it, otherwise a message guides the user to introduce the correct value. The table INSITU_TESTS contains information resulting from any in situ test carried out in boreholes, mainly Standard Penetration test (SPT) and permeability tests. Moreover, this table gathers results from dynamic tests (down-hole and cross-hole). The table LAB TESTS contains data detailing the results of all typical laboratory tests for soil and rock specimen carried out on the investigation samples. ROCKMASS_CLASS table refers to the Rock Mass Rating (RMR) by Bieniawski or Geological Strength Index (GSI) by Hoek. The information can be achieved by studying core samples.

Except primary tables, a few secondary tables have been constructed to lead the user to the correct implementation of data. Those tables include the classification of ISRM to the degree of weathering, the joint spacing, the joint roughness and waviness, and the infilling material in joints. If the user introduces a different value than the expected, an alert message guides him/her for the correct value. An overall picture of the database with primary and secondary tables is shown in Fig. 2. 


\section{A. A. Antoniou et al.}

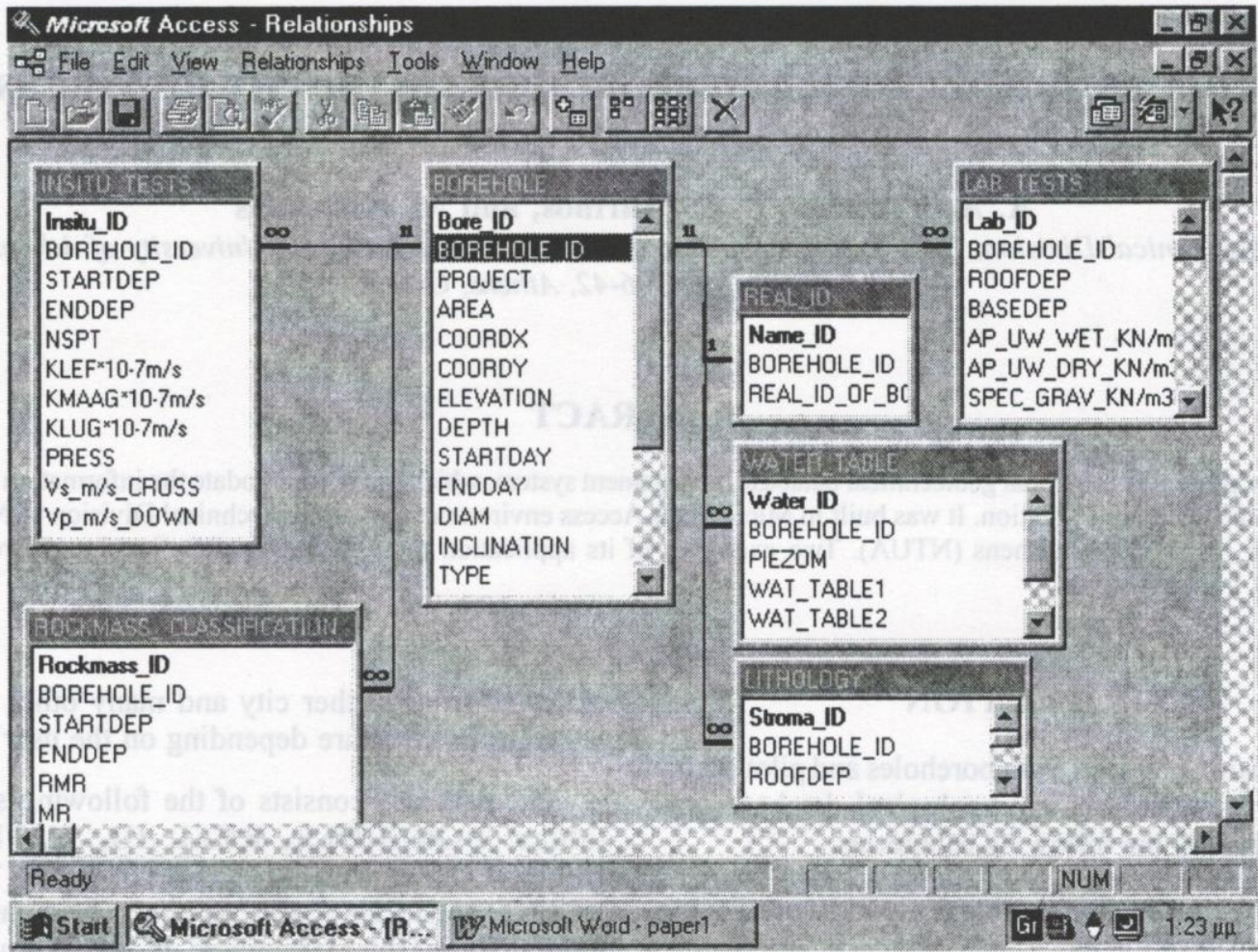

Fig. 1: Structure of the database in MS Access environment

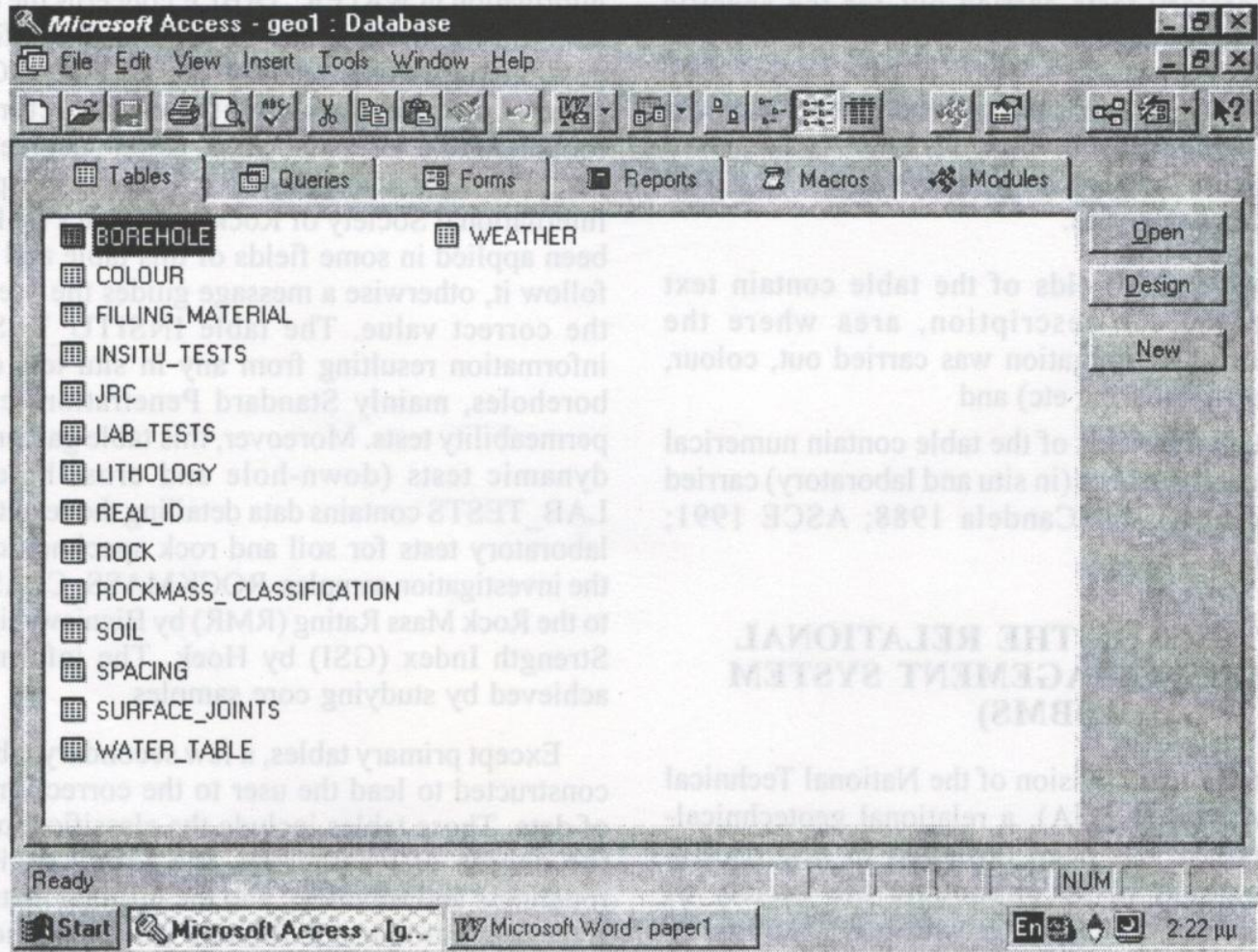

Fig. 2: Overall picture of the database 


\section{Data input}

Data input is done using several forms. The main form is BOREHOLE, and the user inputs the data through it using command buttons associated with the other main forms (Fig. 3).

\section{Data retrieval}

For data retrieval, several queries can be executed. They provide information on various attributes such as SPT tests at a specific place and depth, results from a permeability test at the same place, occurrence of weak material at a specific place etc.

\section{APPLICATION OF "RDBMS" IN A SECTION OF ATHENS}

The city of Athens lies between four mountains and has a "horseshoe" shape with its open part towards the sea. The central part of the city consists of a flysch-type formation known as the Athenian Schist. This formation contains schist, shale, sandstone, siltstone, marl, marly limestone, limestone, and all the intermediate lithological types. Due to tectonic movements and depending on the degree of weathering, the system exhibits a variety of geotechnical behaviour, from rock-like to soil-like (Marinos et al. 1974; Marinos 1983).

Neogene marl, conglomerate, and breccia are exposed in the northern and western parts of the city, and they are followed by well-cemented lateral debris. On the other hand, loose materials (recent deposits, riverbed materials, and alluvium) prevail in the southern part.

Fig. 4 shows the result of running one of the alreadyprepared queries of the database: "Occurrence of the weak black shale between two areas in the city of Athens".

\section{MAPPING THROUGH A GEOGRAPHIC INFORMATION SYSTEM}

Since there are fields that contain the coordinate X, Y, and elevation $\mathrm{Z}$, it is very easy to link or to implement the database to a Geographic Information System (GIS) such as Arcview ${ }^{\circledR}$ (ESRI 1997) and obtain the advantages of those systems. Fig. 5 shows boreholes graduated to depth, all executed to an area of Athens.

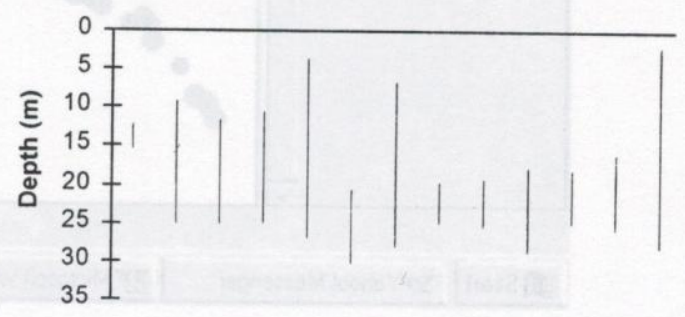

Fig. 4: Occurrence of the weak shale formation (vertical bars) in a sector of the city of Athens (information provided up to the end of each bar), after Kafe (1998)

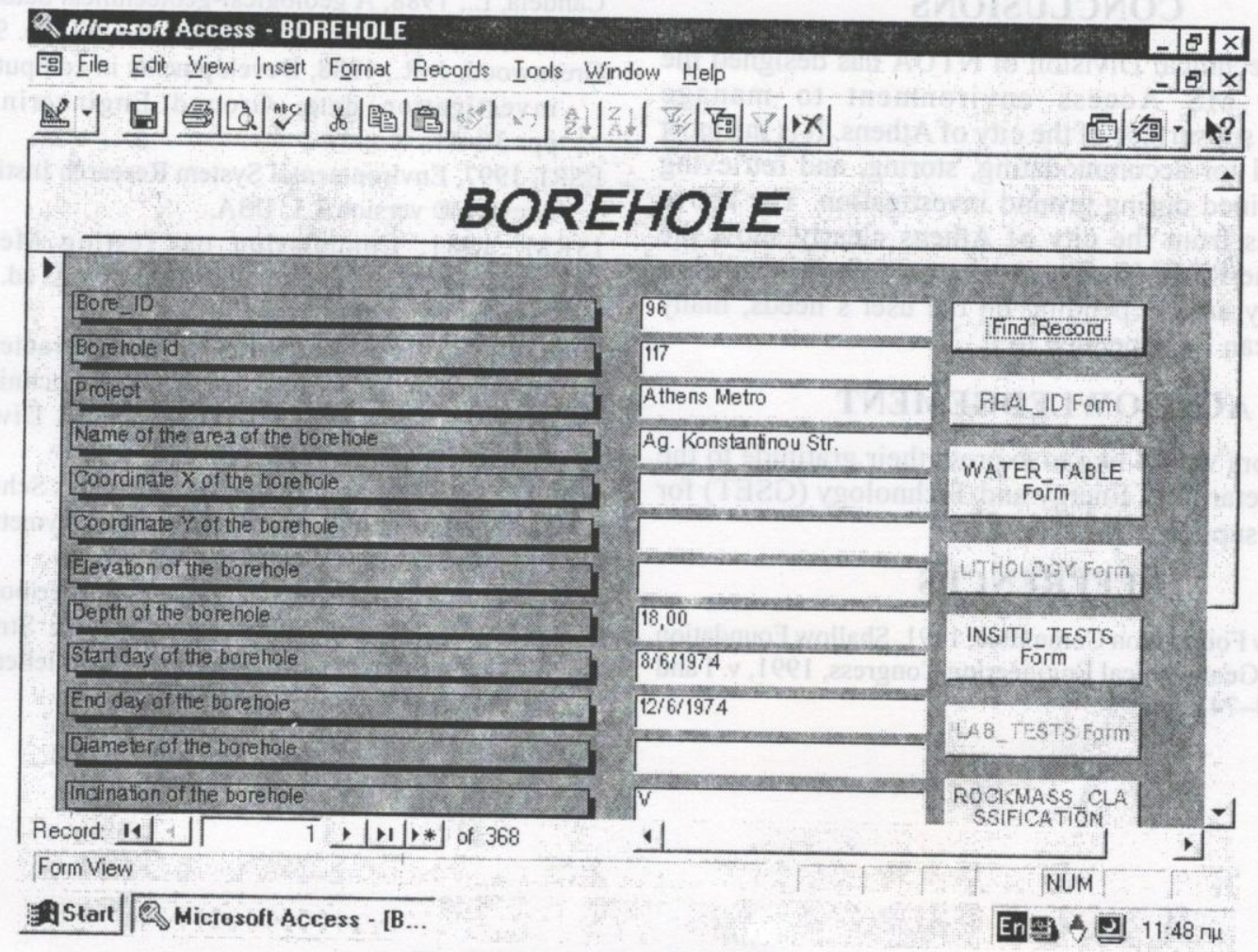

Fig. 3: Main form of the database 


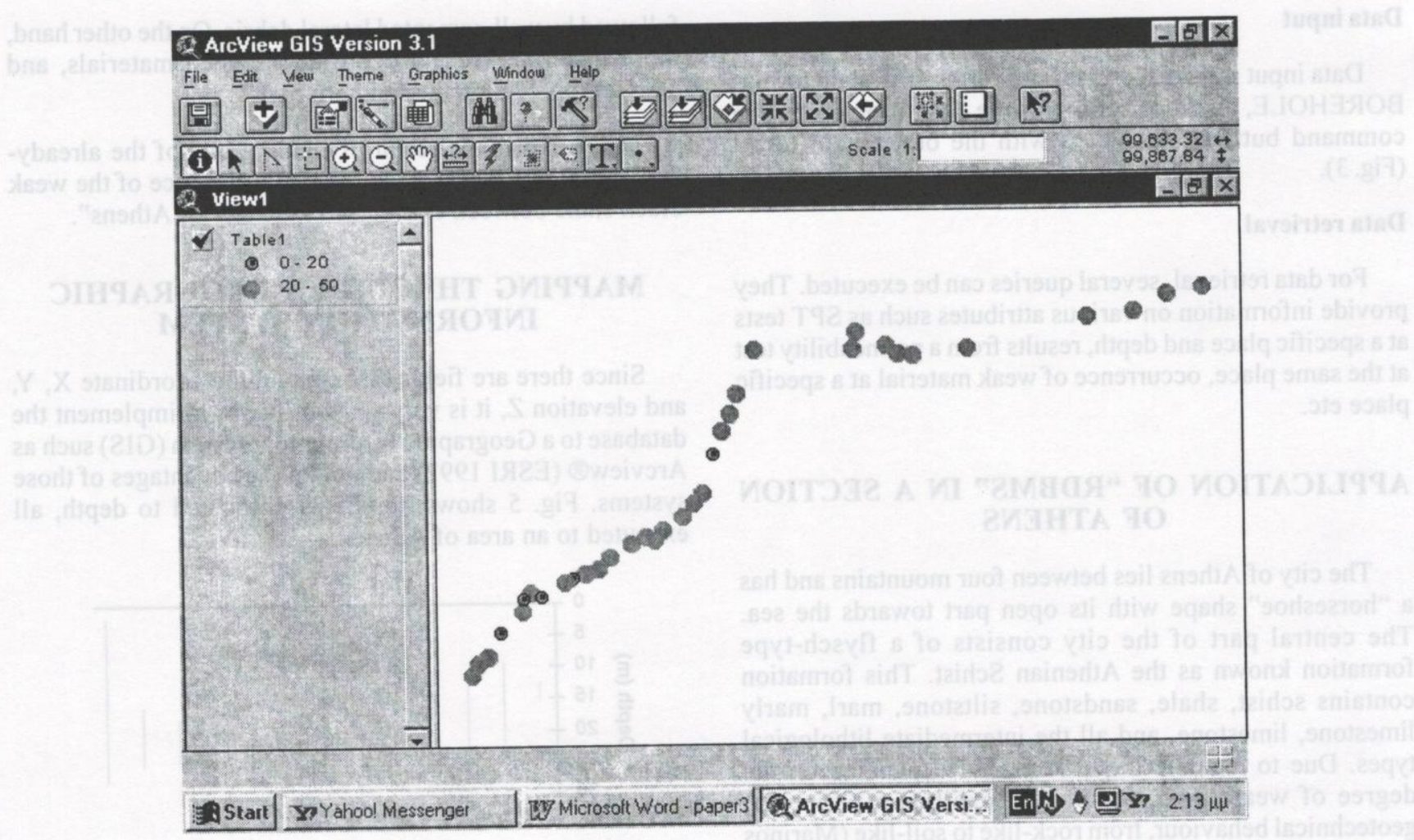

Fig. 5: Boreholes executed in an area of Athens. Different symbols denote respective graduated depths (GIS Arcview 3.1)

\section{CONCLUSIONS}

The Geotechnical Division of NTUA has designed the RDBMS in MS Access environment to manage data from the subsurface of the city of Athens. It is the most powerful tool for accommodating, storing, and retrieving the data obtained during ground investigation. The above two examples from the city of Athens clearly show the strength of the RDBMS. The database can be extended to any other city and, depending on the user's needs, many other tables can be appended to it.

\section{ACKNOWLEDGEMENT}

The authors would like to express their gratitude to the General Secretariat of Energy and Technology (GSET) for the financial support.

\section{REFERENCES}

ASCE Shallow Foundation Committee, 1991, Shallow Foundation Database, Geotechnical Engineering Congress, 1991, v. I and II, pp. 733-741.
Candela, L., 1988, A geological-geotechnical database for micro computers. Bull. of IAEG, Paris, No. 37, pp. 99-106.

Greenwood, J. R., 1988, Developments in computerized ground investigation data. Ground Engineering, v. 21(6), pp. 36-41.

ESRI, 1997, Environmental System Research Institute, Inc., GIS Arcview ${ }^{\circledR}$ version 3.1, USA.

ISRM, 1981, Commission on Testing Methods, Rock Characterisation Testing and Monitoring. ed. E. T. Brown, Pergamon Press.

Kafe, D., 1998, Presentation of the characteristics of the Athenian Schist system through a geotechnical-geological database. Diploma thesis, Geotechnical Division, NTUA, Athens.

Marinos, G., 1983, La position tectonique des Schists d' Athenes sur le complexe metamorphique du mont Hymette, Proceedings of Athens Academy, v. 58, pp. 232-240.

Marinos, G., Katsikatsos, G., and Mirkou-Peripopoulou, P. M., 1974, The Athens Schist formation, II. Stratigraphy and Structure, Annales Geologiques des Pays Helleniques, Athens, pp. 439-444. 